\title{
Advancing Equity for Students with Disabilities in School Sports
}

\author{
Terri Lakowski \\ Lakowski Consulting
}

In 2006, one athlete's fight for inclusion in her high school track team became the symbol and rallying cry for a national movement to expand opportunities for individuals with disabilities in school sports.

Tatyana McFadden, a female high school athlete with a disability, sued her school and her state athletic association to gain access to her high school track team. McFadden was a Paralympic athlete in track and field who won medals in the 2004 Paralympic Summer Games, becoming one of the youngest Paralympians in history. She had spina bifida, was paralyzed from the waist down, and used a wheelchair to compete in track and field. Due to her disability, McFadden's school prohibited her from racing on the track at the same time as other athletes. Instead, it forced her to race by herself at meets, as an "Exhibition" (McFadden v. Grasmick).

When this case came across my desk at the Women's Sports Foundation (Foundation, $)^{1}$ it seemed like deja vu. Just 35 years ago, before the passage of Title IX, schools were engaging in the same discriminatory treatment toward all female athletes - slamming the doors of opportunity in young girls' faces for no other reason than because they were female. Now, history was repeating itself; the doors of opportunity were being slammed shut in the face of a young female athlete, but for a different reason-because she has a disability. Tatyana's case does not represent one isolated incident of discrimination, but is part of a culture of exclusion and discrimination against individuals with disabilities within school systems.

\section{An Overview of Opportunities for Students with Disabilities}

More than fifty million people in the United States (1 out of 6 people) have documented disabilities, yet individuals with disabilities are not getting the same amount of physical activity and athletic opportunities as individuals without disabilities (United States Census Bureau; Department of Health and Human Services). Individuals with disabilities are almost three times as likely to be sedentary as individuals without disabilities (29\% vs. 10\%) (Patricia, 1994). In fact, $56 \%$ of people with disabilities do not engage in any physical activity, and only $23 \%$ of

Lakowski is with Lakowski Consulting LLC, and is Inclusive Fitness Coalition Policy Working Group Chair. 
people with disabilities are active for at least thirty minutes three or more times per week (Patricia, 1994).

The benefits of sports participation are significant for people with disabilities. Physical activity improves academic success, builds self-esteem, and prevents health problems. It reduces the risk of developing heart disease, helps control weight, builds lean muscle, reduces fat, and prevents osteoporosis (National Center for Chronic Disease Prevention and Health Promotion). In addition, sport is where people can develop skills like teamwork, goal-setting, the pursuit of excellence in performance, and other achievement-oriented behaviors necessary for success in schools and the workplace.

Despite these benefits, opportunities for students with disabilities to compete in intercollegiate and interscholastic sports are extremely limited. The National Collegiate Athletic Association (NCAA) and the National Federation of State High School Associations (NFSHSA) do not officially sanction any intercollegiate or interscholastic program, event or competition for individuals with disabilities. In the absence of standardized national or state competition for students with disabilities, some states, school districts, or individual schools have voluntarily accommodated students with disabilities into already existing programs (a process known as "mainstreaming") or, in very limited instances, created adapted sports programs specifically for students with disabilities.

However, this action is not unilateral. More often than not, the experiences of students with disabilities mirror the story of Tatyana McFadden described at the beginning of this article: they are not provided with reasonable accommodations; they are included but ostracized because of the disability, or they are completely excluded from participation because of their disability.

\section{The Need for a Policy Solution}

There is a need to expand physical activity and athletic opportunities for individuals with disabilities in our educational institutions. Individuals with and without disabilities, female and male, must be provided with equal opportunities and resources to participate in school-based athletic programs. The current state of athletic opportunities for students with disabilities calls for legislative and regulatory intervention.

\section{The Issue}

The Department of Education (ED) issued regulations under the Rehabilitation Act of 1973 that specifically address interscholastic and intercollegiate sports. The regulations require that students with disabilities be offered equal opportunities to participate in interscholastic and intercollegiate athletics. While these regulations call for the provision of "equal opportunity," ED provides no further guidance in the regulations as to what exactly constitutes "equal opportunity" in school sports.

Does "equal" mean that students with disabilities can try out for teams, but schools do not have to provide any type of accommodation for their disability? Or, as in the case of the Tatyana McFadden from Maryland, should "equal" simply mean a chance to participate, but not as a fully integrated member of a team? Or, as I will argue, should "equal" mean providing students with disabilities access 
to similar opportunities for meaningful participation as that provided for students without disabilities?

The lack of specificity regarding the meaning of "equal opportunity" presents a constant source of conflict between students and school administrators.

\section{The Title IX Analogy}

The success of Title IX, the landmark legislation that prohibits sex discrimination in schools, in expanding opportunities for women and girls in sports provides a useful model for creating a structure to expand opportunities for students with disabilities. Before the passage of Title IX, few schools offered interscholastic or intercollegiate athletic teams for girls. Since the passage of Title IX, female participation in athletics has expanded over $904 \%$ at the high school level $(294,015-3,021,807)$ and over $456 \%$ at the college level $(29,977-166,728)$ (Denise, M. DeHass; National Federation of State High School Associations).

The language of the Rehab Act is nearly identical to the language of Title IX. Title IX provides that:

"No person in the United States shall, on the basis of sex, be excluded from participation in, be denied the benefits of, or be subjected to discrimination under any education program or activity receiving Federal financial assistance. ..." (Title IX of the Education Amendments of 1972)

Similarly, the Rehab Act provides that:

"No otherwise qualified individual with a disability ... shall, solely by reason of her disability, be excluded from participation in, be denied the benefits of, or be subjected to discrimination under any program or activity receiving Federal financial assistance. ..." (Rehab Act)

While the statutory language of Title IX and the Rehab Act mirror each other, the legislative acts differ in the level of specificity in the regulations pertaining specifically to athletics. Title IX has been so successful, unlike the Rehab Act, because it contains detailed regulations that clearly define schools' obligations to provide women and girls with athletic opportunities_-including the specific requirement that schools create separate teams for girls and women. Specifically, Title IX requires that a school must offer a separate team for girls under the following conditions:

(1) The opportunities for members of the excluded sex have historically been limited; and

(2) There is sufficient interest and ability among the members of the excluded sex to sustain a viable team and a reasonable expectation for intercollegiate competition for that team. ...

(3) The members of the excluded sex do not possess sufficient skill to be selected for a single integrated team, or compete actively on such a team if selected (Title IX and Intercollegiate Athletics).

This regulatory framework translates to the disability context and should be implemented to ensure that sports opportunities for students with disabilities expand in the same manner as they have for women under Title IX. 


\section{Policy Recommendations}

In June 2010, following the heroic and concerted efforts of over 100 groups comprising the Alliance for Athletic Equity for Students with Disabilities, ${ }^{2}$ the Government Accountability Office (GAO) completed its first ever study on the state of physical activity and athletic opportunities for students with disabilities. This study found that students with disabilities participate in athletics at consistently lower rates than students without disabilities. District and school officials that GAO interviewed cited a lack of information on ways to expand athletic opportunities for students with disabilities and a lack of clarity regarding school's responsibilities under Section 504 of the Rehabilitation Act as two key barriers to providing opportunities. As a result, the GAO recommended the Department of Education clarify and communicate school's responsibilities under the Rehab Act regarding the provision of extracurricular athletics opportunities.

To ensure that institutions fully understand what is required to provide equal opportunities to students with disabilities in athletics, ED should borrow from the success of the regulatory framework of Title IX and translates it to the disability context.

Specifically, under the Rehab Act, ED should promulgate regulations clarifying that schools must offer a separate team for students with disabilities under the following conditions:

(1) the opportunities for students with disabilities have historically been limited;

(2) there is sufficient interest and ability to sustain a viable team;

(3) there is a reasonable expectation for competition for that team; and

(4) the students with disabilities, even with reasonable accommodations, do not possess sufficient skill to be selected for a single integrated team or compete actively on such a team if selected.

The creation of these regulations would supplement, not replace, the existing regulations that require students with disabilities to always have the opportunity to try out for the mainstream team. These new regulations would give students with disabilities the opportunity to compete on mainstream teams and to participate in adapted programs for students with disabilities.

Furthermore, additional guidance is needed to clarify the meaning of "equal opportunity" in the Rehab Act regulations. Title IX provides a solid model to address this issue as well. The Title IX regulations outline what "equal opportunity" means for men and women in sports, and specifically requires that the athletic benefits and resources afforded to both men's and women's programs be comparable. The equivalence of overall treatment is measured on the basis of eleven criteria: locker room, practice and competitive facilities, equipment and supplies, scheduling of games and practice times, publicity, coaching, travel and daily allowance, academic tutoring, medical and training facilities and services, housing and dining facilities and services, recruitment of student athletes, and support services. This same standard also must be articulated in the context of athletic opportunities for student athletes with disabilities.

ED should promulgate regulations clarifying that equal opportunity for students with disabilities means that the overall benefits and treatment afforded them and 
student athletes without disabilities are comparable. This includes: locker room, practice and competitive facilities, equipment and supplies, the scheduling of games and practice times, publicity services, coaching, the provision of travel and daily allowance, access to academic tutoring, medical and training facilities and services, housing and dining facilities and services, the recruitment of student athletes, and the provision of athletic support services.

These guidelines require a holistic approach by schools seeking to comply with the Rehab Act and ensure that schools look broadly and proactively to include students with disabilities in athletic programs to satisfy their civil rights obligations to provide equal educational opportunities.

\section{Conclusion}

Today, as we look at the historic milestones of Title IX, we must ask ourselves if such advances would have been possible if in the early stages of compliance if State Departments of Educations or individual school systems had developed their own approach to 'sport' for women and girls. What if the high school associations and the NCAA had not eventually embraced the inclusion of girls in athletics and the standardization of their sports? How could female athletes possibly have gained essential recognition as participants in "real sports", thwarting the misconceptions of early detractors and critics? How could those sports and athletic programs have taken hold in our communities if such differences in approaches and a lack of infrastructure support had been allowed to exist without forethought?

Standardization and inclusion within the existing infrastructures of interscholastic and intercollegiate athletics for persons with disabilities must become a goal that we all support and encourage in unison. Sports are too potent a force in society and have too much of an impact on an individual's health, confidence, and self-esteem for us not to do everything we can to ensure that sports girls and boys with disabilities are treated as well, and have the same opportunities for participation, as sports girls and boys without disabilities. Anything less is not true "equity."

\section{Notes}

1. Terri Lakowski was the Public Policy Director at the Women's Sports Foundation from 2005 to 2010 .

2. The response of the Alliance for Athletic Equity for Students with Disabilities to the GAO study can be found at http://www.adaptedsports.org/adaptedsports/media/pr_43.html and the Full Report on this GAO Study can be downloaded at: http://www.gao.gov/Products/GAO-10-519.

\section{References}

Denise, M. DeHass, National Collegiate Athletic Association, 1981-82 - 2007-08 NCAA Sports Sponsorship and Participation Rates Report 57, 203 (2009), available at http:// www.ncaapublications.com/Uploads/PDF/ParticipationRates2009c2f40573-60aa-4a08874d-1aff4192c5e4.pdf. 
Department of Health and Human Services. Healthy People with Disabilities http://www. cdc.gov/ncbddd/factsheets/DH_hp2010.pdf (last visited May 7, 2009).

McFadden v. Grasmick, 485 F. Supp. 2d 642, 643 (D. Md. 2007); Complaint at 3, McFadden v. Cousin, No. AMD 06-648 (D. Md. Mar. 10, 2006).

National Center for Chronic Disease Prevention and Health Promotion. U.S. Dep't of Health and Human Services, Physical Activity and Health: A Report of the Surgeon General 29 (1996), available at http://www.cdc.gov/nccdphp/sgr/pdf/sgrfull.pdf.

National Federation of State High School Associations, 2007 Athletic Participation Data (2007). Rehabilitation Act of 1973, 20 U.S.C. $§ 1681(a)$.

Patricia, E. (1994). Longmuir \& Oded Bar-Or, Physical Activity of Children and Adolescents with a Disability: Methodology and Effects of Age and Gender, 6. Pediatric Exercise Science, $X X X, 168$.

Title IX of the Education Amendments of 1972; 20 U.S.C. § 1681(a) (1976).

Title IX and Intercollegiate Athletics, 44 Fed. Reg. 71413, 71418 (Dec. 11, 1979).

United States Census Bureau. Annual Estimates of the Population for the United States, Regions, and States and for Puerto Rico: April 1, 2000 to July 1, 2006, http://www. census.gov/popest/states/tables/NST-EST2006-01.xls (last visited Feb 28, 2009). 